\title{
Use of nitrous oxide in children with special health care needs
}

\section{Priyanshi Ritwik $^{1}$ (D) Kunal Gupta ${ }^{2}$}

Received: 26 May 2020 / Accepted: 9 September 2020 / Published online: 27 October 2020

(c) Springer Nature Switzerland AG 2020

\begin{abstract}
Providing optimal oral health care for children and individuals with special health care needs (SHCN) is an integral professional and ethical responsibility of dentists. Children with special health care needs may have behavioral factors, medical complexities, and/or intellectual disabilities which influence their ability to cooperate for dental treatment. They may have elevated dental fear and anxiety which may not be alleviated with basic behavior guidance strategies alone. The option to offer inhalational nitrous oxide provides an adjunctive method to help reduce a child's pain and anxiety during dental treatment. Inhalational nitrous oxide can be simply administered via a well-fitting nasal hood. Based on the underlying medical condition of the child, it may be necessary to monitor oxygen saturation with pulse oximetry. Administration of $100 \%$ oxygen preoperatively and upon completion of treatment is an essential step applicable to all the patients. Children recover quickly from the effects of nitrous oxide after post-treatment oxygenation and can be discharged to the parent without any residual effects. With appropriate case selection and administration technique, inhalational nitrous oxide is a safe and effective technique to provide dental treatment for children with special health care needs.
\end{abstract}

Keywords Children with special health care needs $\cdot$ Anxiolysis $\cdot$ Nitrous oxide Sedation

\section{Quick reference/description}

Delivery of optimal dental treatment for children with special health care needs may be significantly challenging for dentists. Inhalational nitrous oxide is a vital adjunct for dentists to provide safe and effective care for this vulnerable patient population.

Priyanshi Ritwik

Priyanshi.ritwik@uth.tmc.edu

1 Department of Pediatric Dentistry, University of Texas Health Science Center at Houston School of Dentistry, 7500 Cambridge St, Suite 5301, Houston, TX 77054, USA

2 Children's Dental Center, Gurugram, India 
Anxiolysis, analgesia, and a wide margin of safety and ease of delivery are some of the key attributes of nitrous oxide which support its utilization. Successful utilization of nitrous oxide sedation can avoid the use of general anesthesia for these children and hence avoid the associated risks.

\section{Overview}

\begin{tabular}{|c|c|c|}
\hline $\begin{array}{l}\text { Medical conditions in children } \\
\text { requiring special health care }\end{array}$ & $\begin{array}{l}\text { Indications for the use of nitrous } \\
\text { oxide }\end{array}$ & $\begin{array}{l}\text { Contraindications for the use of } \\
\text { nitrous oxide }\end{array}$ \\
\hline Asthma & $\begin{array}{l}\text { Children with well-controlled } \\
\text { intermittent and mild persistent } \\
\text { asthma without a recent or } \\
\text { active episode }\end{array}$ & $\begin{array}{l}\text { Children with moderate or severe } \\
\text { persistent asthma with frequent } \\
\text { active episodes }\end{array}$ \\
\hline $\begin{array}{l}\text { Attention Deficit Hyperactivity } \\
\text { Disorder (ADHD) }\end{array}$ & $\begin{array}{l}\text { Children with ADHD for tolerat- } \\
\text { ing lengthy appointments with } \\
\text { fewer incidences of disruptive } \\
\text { behavior }\end{array}$ & No absolute contraindications \\
\hline $\begin{array}{l}\text { Autism Spectrum Disorder } \\
\text { (ASD) }\end{array}$ & $\begin{array}{l}\text { A child with level } 1 \text { severity of } \\
\text { ASD } \\
\text { A child with level } 2 \text { severity of } \\
\text { ASD }\end{array}$ & $\begin{array}{l}\text { A non-communicative or physi- } \\
\text { cally combative child } \\
\text { In children with ASD having } \\
\text { congenital abnormalities or } \\
\text { comorbid conditions }\end{array}$ \\
\hline Cerebral Palsy (CP) & $\begin{array}{l}\text { As an adjunct to behavior guid- } \\
\text { ance in children with } \mathrm{CP} \text { for } \\
\text { effective dental treatment }\end{array}$ & $\begin{array}{l}\text { Children with physically combat- } \\
\text { ive behavior } \\
\text { Children with uncontrolled move- } \\
\text { ment which displaces the nasal } \\
\text { hood }\end{array}$ \\
\hline Epilepsy & $\begin{array}{l}\text { Children with controlled seizures } \\
\text { for elective dental care in out- } \\
\text { patient setting } \\
\text { To reduce anxiety in patients } \\
\text { with epilepsy }\end{array}$ & $\begin{array}{l}\text { In children with seizures due to } \\
\text { acute head injury } \\
\text { In children with uncontrolled } \\
\text { seizures }\end{array}$ \\
\hline Sickle Cell Disease (SCD) & $\begin{array}{l}\text { To alleviate dental fear and anxi- } \\
\text { ety in a child with SCD } \\
\text { To prevent precipitation of sickle } \\
\text { cell crisis }\end{array}$ & Episodes of sickle cell crisis \\
\hline Diabetes Mellitus (DM) & $\begin{array}{l}\text { Children with type I and type II } \\
\text { DM having sufficient glycemic } \\
\text { control and good compliance } \\
\text { with medical care }\end{array}$ & $\begin{array}{l}\text { Diabetic children with inadequate } \\
\text { glycemic control and non-com- } \\
\text { pliance with medications }\end{array}$ \\
\hline Intellectual Disability & $\begin{array}{l}\text { To eliminate or minimize severe } \\
\text { gagging in children with intel- } \\
\text { lectual disability } \\
\text { To prevent exposure to general } \\
\text { anesthesia and associated } \\
\text { risks for the delivery of dental } \\
\text { treatment }\end{array}$ & $\begin{array}{l}\text { Children with physically combat- } \\
\text { ive behavior }\end{array}$ \\
\hline
\end{tabular}


Medical conditions in children requiring special health care
Indications for the use of nitrous oxide
Contraindications for the use of nitrous oxide

\begin{tabular}{lcc}
\hline $\begin{array}{l}\text { Congenital and Acquired Heart } \\
\text { Disease }\end{array}$ & $\begin{array}{c}\text { Children with acyanotic condi- } \\
\text { tions who have been medically } \\
\text { cleared for dental treatment in } \\
\text { an out-patient setting }\end{array}$ & $\begin{array}{l}\text { If the child is cyanotic at rest or } \\
\text { baseline, performing dental care } \\
\text { in non-hospital setting should } \\
\text { be discussed with the pediatric } \\
\text { cardiologist }\end{array}$ \\
\hline
\end{tabular}

\section{Materials/instruments}

- Albuterol inhaler

- Spacer

- Rubber dam

- High volume suction

- Nitrous oxide delivery hood

- Oxygen E cylinder (for emergencies)

- Pulse oximeter

- Acrylic obturator

- Gauze

- Dental floss

\section{Procedure}

One of the most challenging tasks for dentists is to provide safe and effective dental care for children with special health care needs. Providing effective treatment is particularly challenging in this patient population due to altered physiological parameters, limitations in communication, atypical neurodevelopment, and/or absence of typical motor coordination. The aforementioned difficulties are complicated by the anxiety and fear associated with dental care. The use of nitrous oxide in children with special health care needs alleviates this fear and anxiety and has the potential to reduce the number of children receiving dental care under general anesthesia.

\section{Technique of inhalational nitrous oxide administration in children}

The technique for administration of nitrous oxide in children with special health care needs is similar to that in healthy children. In children with special health care needs, pre- and post-oxygenation with $100 \%$ inhalational oxygen is necessary to reduce any probable adverse events. Post-treatment oxygenation should be continued for at least 5 min after treatment completion. The use of rubber dam isolation and high-volume suction is imperative to prevent the secretions and aerosols generated during dental treatment from triggering any underlying disease episodes (Fig. 1). 
Fig. 1 Dental care with inhalational nitrous oxide and rubber dam isolation

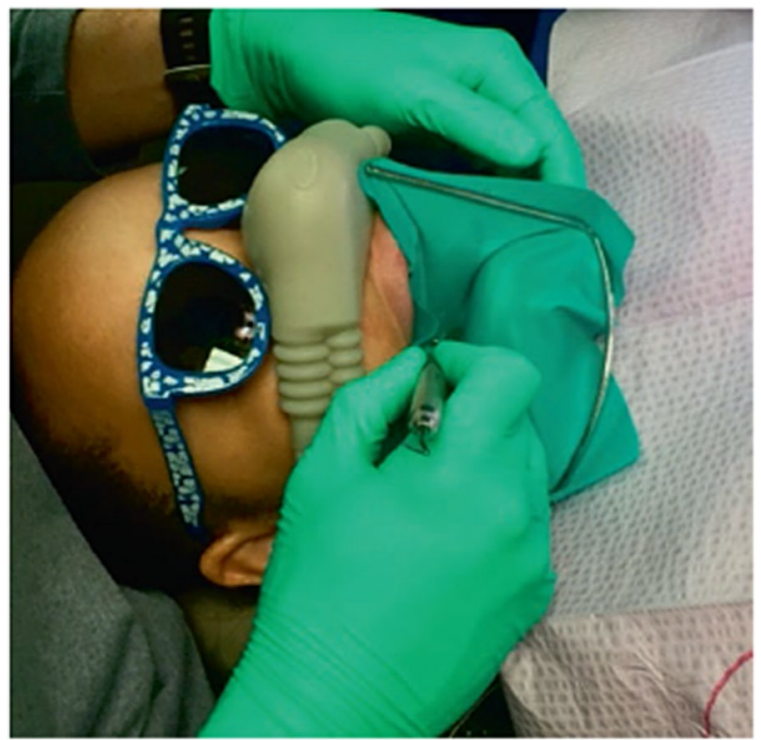

\section{Nitrous oxide sedation in children with special health care needs}

Utilization of inhalational nitrous oxide after a thorough review of medical history and careful case selection is advantageous in children with special health care needs due to its wide margin of safety and its analgesic and anxiolytic properties. Desensitization, pre- and post- oxygenation, and continual basic behavior guidance are key factors for optimal outcomes with nitrous oxide inhalation in children with special health care needs.

\section{Asthma}

Asthma is a chronic lung disorder characterized by bronchoconstriction, resulting in a narrow airway. The symptoms of asthma are coughing, chest tightness, wheezing, and shortness of breath. The classification of asthma depends on the frequency and severity of symptoms. This classification and preoperative patient assessment are essential to determine an appropriate candidate for nitrous oxide sedation (Table 1). Children with controlled intermittent and mild persistent asthma without an active or recent episode are indicated for dental care with inhalational nitrous oxide.

Preoperative assessment To establish the suitability of nitrous oxide sedation for anxiolysis in children with asthma, a detailed medical history is mandatory. This anamnesis should include severity and frequency of symptoms, nocturnal episodes, functional impairment, number of medications, level of control, and treatment compliance. These key factors should be discussed with the parents before considering 


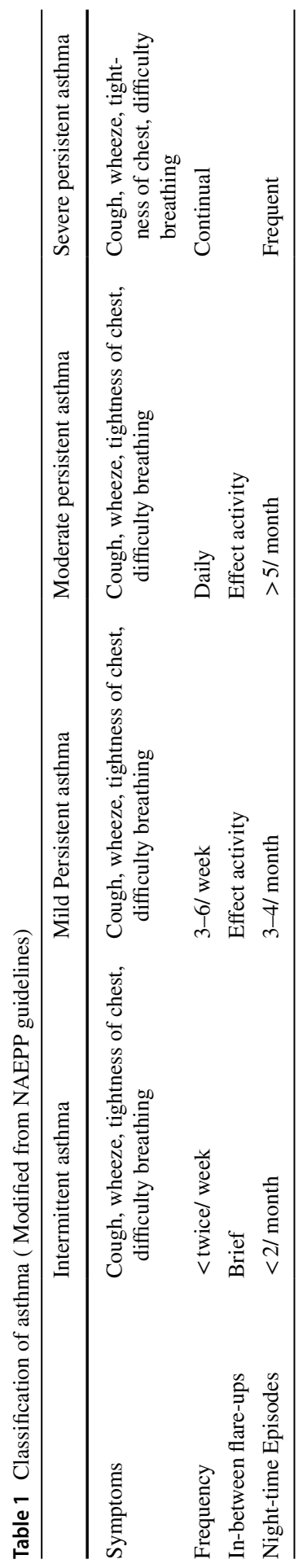


nitrous oxide administration. If the child's parents cannot provide appropriate information, the pediatric pulmonologist should be consulted.

Technical considerations Nitrous oxide sedation results in anxiolysis that decreases the likelihood of precipitating stress-induced asthma during dental care. The child and the parent should be advised to bring the child's albuterol inhaler for the dental appointment as it has the most effective dose titrated for the child. The use of nitrous oxide in children with asthma is similar to that in healthy children, with emphasis on pre- and post-oxygenation.

The dental clinic should have an albuterol inhaler in the emergency medication kit (Fig. 2a). A spacer to aid rescue albuterol intake should be available in every dental office that treats young children (Fig. 2b). Nitrous oxide sedation is a safe and effective method to facilitate dental treatment in asthmatic children with dental fear and anxiety following a thorough anamnesis and appropriate administration technique.

\section{Attention deficit hyperactivity disorder}

Attention deficit hyperactivity disorder (ADHD) is a neurobiological behavioral condition that manifests in early childhood and can continue into adulthood. Its features include inattention, hyperactivity, and impulsivity.

Technical considerations Children with ADHD are usually talkative or restless leading to behavioral disruptions during dental appointments. Hence, the children should be educated about the treatment procedure before performing the treatment. The initial appointment should help to develop a personal rapport with the child and use the tell-show-do method for introducing the dental care procedure. Nitrous oxide administration may be demonstrated by modeling. As part of the tell-show-do technique, the child can be introduced to the nitrous oxide delivery unit and allowed to touch the

(a)

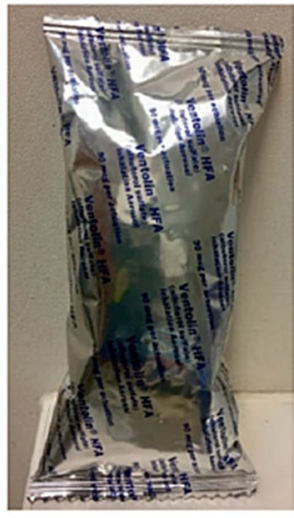

(b)

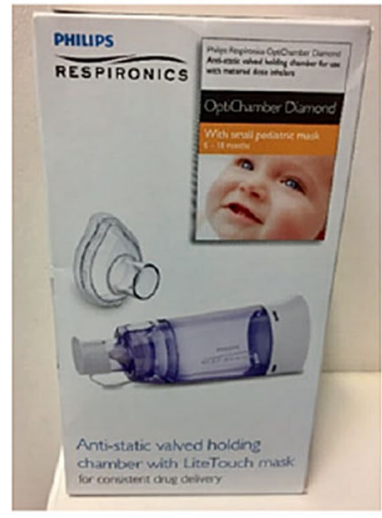

Fig. 2 a Albuterol b Spacer for young children with asthma 
components. The child can be provided a disposable nitrous oxide nasal hood to take home to practice placing it on their nose and breathing.

Nitrous oxide inhalation allows children with ADHD to undergo lengthy dental appointments with infrequent episodes of disruptive behavior. Dental appointments should be held in the morning as most children with ADHD receive their medication in the morning. Nitrous oxide does not interact with the medications for ADHD. Along with important basic behavior guidance strategies, such as short morning appointments, short scheduled breaks, and positive reinforcement, inhalational nitrous oxide is a safe and effective method for facilitating dental treatment in children with ADHD.

Children with ADHD should be instructed with short clear instructions. The dentist should give instructions, such that they are one step of the procedure at a time. Empowering the child by allowing them to use a signaling system and distraction by counting out may be utilized. Counting can be slowly increased based on the child's cooperation. The technique of nitrous oxide administration in children with ADHD is the same as for healthy children with emphasis on pre- and post-oxygenation.

\section{Autism spectrum disorder}

Autism spectrum disorder (ASD) is a developmental disorder that is identified within 0-2 years of age. It affects behavior and communication. Due to the variation in severity and type of symptoms, autism is considered as a spectrum disorder. The DSM-V classification describes the classic features of ASD (Table 2).

Table 2 DSM-V classification for features of autism spectrum disorder

\begin{tabular}{ll}
\hline A. Persistent deficits in social communication and & Deficits in social-emotional reciprocity \\
social interaction across multiple contexts & Deficits in nonverbal communicative behaviors used \\
& for social interaction \\
& Deficits in developing, maintaining, and understand- \\
& ing relationships
\end{tabular}

B. Restricted, repetitive patterns of behavior, inter- Stereotyped or repetitive motor movements, use of ests, or activities, as manifested by at least two of the following, currently or by history

objects or speech

Insistence on sameness, inflexible adherence to routines, or ritualized patterns or verbal-nonverbal behavior

Highly restricted, fixated interests that are abnormal in intensity or focus

Hyper- or hyporeactivity to sensory input or unusual interests in sensory aspects of the environment

C. Symptoms must be present in the early developmental period

D. Symptoms cause clinically significant impairment in social, occupational, or other important areas of current functioning

E. These disturbances are not better explained by intellectual disability (intellectual developmental disorder) or global developmental delay

Inadequate social communication is a good index to look at before, concluding that a child has both intellectual disability and autism spectrum disorder 
Preoperative assessment Poor oral hygiene and dental caries are prevalent in children with ASD and pose significant challenges as they often necessitate complex dental treatments. Children with ASD often have difficulty in accepting dental treatment. A modified adaptation of the severity of autism, depending on communication and function, allows a dentist to evaluate children with ASD to determine their suitability for dental care under nitrous oxide sedation in a dental office (Table 3; Adapted from www.autismspeaks.org and DSM-5).

Biochemical abnormalities associated with vitamin B12 deficiency, folic acid metabolism, and MTHFR deficiency should be identified in children with ASD by asking the parents about it and obtaining a detailed dietary history. In case of presence of any such comorbidities, the use of nitrous oxide should be avoided.

Technical considerations Familiarity, regularity, and repetition are known to enhance behavioral outcomes in children with ASD. Therefore, while considering the use of nitrous oxide in children with ASD, allowing the child to explore and familiarize with the dental operatory and equipment in an environment that does not trigger anxiety is essential. The treatment operatory should be shown to the child. The child should also be allowed to take the disposable hood and try to use it at home. Social narratives, sometimes, referred to as social stories and story-based interventions have been utilized for children with ASD to teach them expected behaviors in specific settings. These can be incorporated in the form of picture books, dental story books, or electronic media to further help a child with ASD prepare for an upcoming dental appointment with inhalational nitrous oxide.

A rapid titration technique for nitrous oxide administration can be used effectively by keeping the delivery hood slightly away from the nose in a sitting or standing position. The approach for nitrous oxide administration in children with ASD is similar to that in healthy children with a special attention towards pre- and postoxygenation. After relaxation, the child should be shifted to the dental chair in the supine position.

To aid calming and relaxation in young children with ASD, a nonpharmacologic and relatively inexpensive intervention is the use of weighted blankets. It is recommended by allied health professionals and can be used along with nitrous oxide sedation for a successful dental appointment.

\section{Cerebral palsy}

Cerebral palsy (CP) is a group of neurological disorders affecting muscular coordination, muscle control, balance, gait, and posture. It usually appears in early childhood with various physical difficulties and behavioral complexities. Commonly, children with CP may require physical therapy, long-term medications, and sedative or muscle relaxants which can affect hepatic metabolism. The use of inhalational nitrous oxide in children with CP is safe as it does not affect hepatic metabolism. It is a valuable adjunct to basic behavior guidance methods to enable dental care in these children as it offers various advantages like:

- Reduces stress 


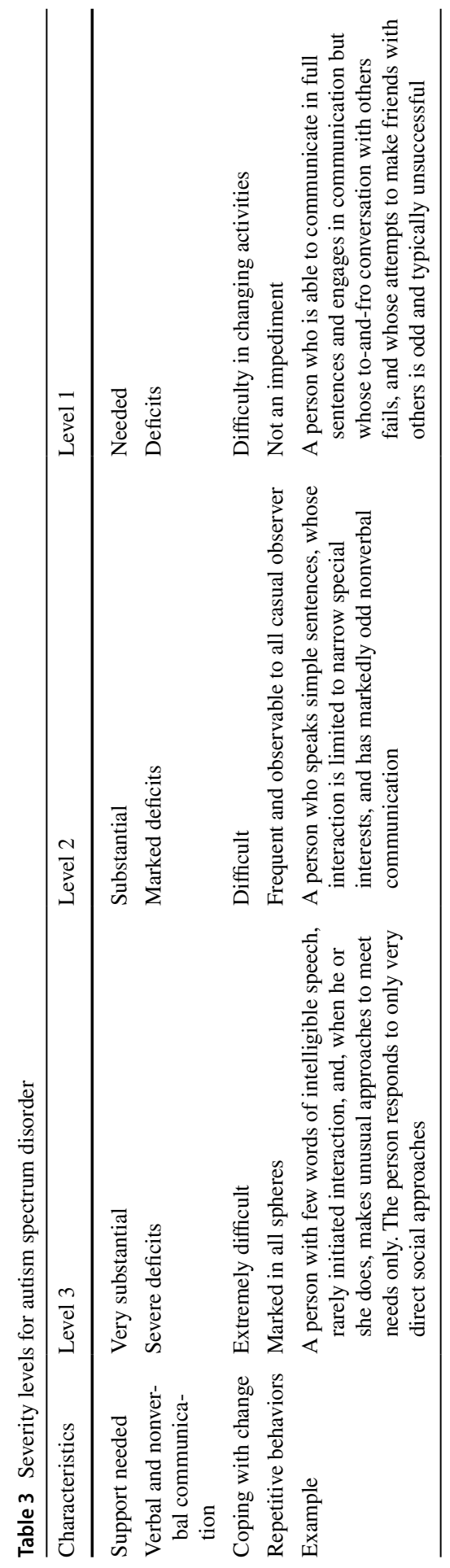


- Improves behavioral compliance

- Enables patient-centered care

- Reduces untoward, uncontrolled movement

- Decreases the orofacial muscle tonus and gag reflex.

Technical considerations While administering nitrous oxide to children with $\mathrm{CP}$, comfortable positioning of the child in the dental chair without forceful repositioning of any body part is imperative. Unique posture of any body part can be due to hypertonic muscles that should be supported by cushions and rolled towels for comfortable positioning. Cushioning of bony prominences like elbows, knees, and ankles is recommended during lengthy dental appointments.

The nitrous oxide delivery hood should be shown to the child. It should then be placed over the child's nose while accommodating the child's natural head position. Forceful redirection of the child's head for convenience of the dentist should be avoided if the head position is in a specific direction due to muscle tone or skeletal adaptations. Following nitrous oxide administration, relaxation of muscle tonus is observed that can naturally reposition the child's head more favorably in the dental chair. The administration technique for nitrous oxide in children with $\mathrm{CP}$ is the same as in healthy children with emphasis on pre- and post-oxygenation to avoid hypoxia.

\section{Epilepsy}

Recurrent seizures are characteristic of epilepsy in children. These seizures can be treated with diet, medications or nerve stimulation devices. Children with epilepsy also require dental treatment and experience dental anxiety, just like their healthy counterparts.

Technical considerations The risk of seizures may increase due to triggers such as dental anxiety, pain, stress, or infection. Nitrous oxide is not epileptogenic. Use of nitrous oxide for anxiolysis during dental care in a child with epilepsy should be based on a detailed evaluation of the medical history, type and frequency of seizures, trigger factors, and treatment compliance. Specifically, on the day of scheduled dental treatment with inhalational nitrous oxide, medication history, and compliance with intake of medications as prescribed by the physician should be verified. It should be used cautiously in children with epilepsy to prevent hypoxia, a trigger factor for the onset of a seizure. The method of nitrous oxide administration in children with epilepsy is the same as for healthy children with pre- and post-oxygenation.

\section{Sickle cell disorder}

Sickle cell disorder (SCD) is an inherited disorder of the red blood cells caused by abnormal hemoglobin. It results in distorted sickle-shaped cells when exposed to dehydration, hypoxia, or stress. It is the most common genetic hematologic disorder and is characterized by chronic hemolytic anemia and intermittent 
vaso-occlusion. Vaso-occlusion can cause sickle cell crisis that presents as episodes of acute and severe pain.

Preoperative assessment Consultation with the treating pediatrician/hematologist is a prerequisite to decide whether dental care should be performed in the dental clinic or a hospital setting. This decision should be based on a thorough anamnesis including:

- Severity of SCD and frequency of sickle cell crisis episodes

- Medications (including antibiotics, folic acid, and nonsteroidal anti-inflammatory drugs)

- Complications secondary to SCD (jaundice, splenectomy, bleeding disorders, renal issues, or growth disorder)

- Compliance with medical management of SCD

Technical considerations Minimizing stress during dental appointments with the use of inhalational nitrous oxide is beneficial for children with SCD. Its administration technique for children with SCD is the same as for healthy children. Pre- and postoxygenation with $100 \%$ oxygen and oxygen saturation monitoring using pulse oximetry during nitrous oxide inhalation is essential in children with SCD. During nitrous oxide inhalation, the child should receive at least $50 \%$ oxygen.

To prevent diffusion hypoxia in children with SCD, continuous oxygenation is mandatory. Pulse oximetry is used to ensure a continuous minimum oxygen saturation of $95 \%$ during nitrous oxide administration (Fig. 3). Maintenance of hydration is vital in children with SCD to prevent the precipitation of sickle cell crisis. Hence, intake of water or a balanced electrolyte solution by the child should be encouraged after the dental treatment under nitrous oxide. The dentist can provide dental care to children with SCD by using nitrous oxide for decreasing dental fear, anxiety, stress, and the probability of a sickle cell crisis.

(a)
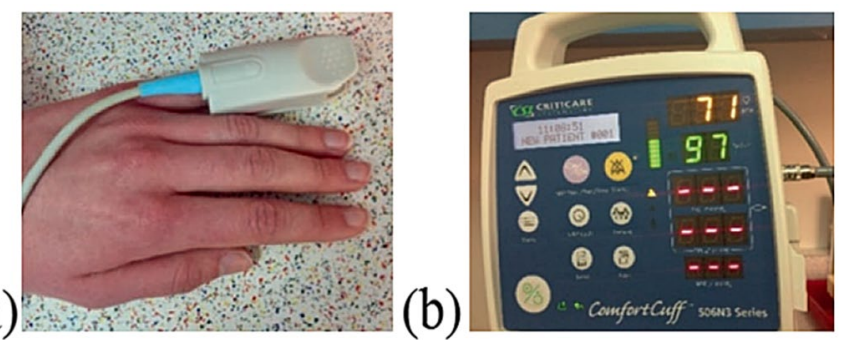

Fig. 3 a, b Use of pulse oximetry in children with SCD or cardiac conditions 


\section{Diabetes mellitus}

Nitrous oxide inhalation can be used successfully to treat children with type 1 or type 2 diabetes mellitus. Prior to treatment initiation, a detailed anamnesis of the child's current and average blood glucose levels, medications, treatment compliance, and consultation with the endocrinologist are necessary. Nitrous oxide can be effectively used to aid dental care in children with sufficient glycemic control and treatment compliance. A special care should be taken to prevent hypoglycemia while scheduling appointments for children with diabetes mellitus.

Technical considerations For children with diabetes mellitus, the dental appointment should be scheduled, such that the 2 -h fasting period does not interference with the timing of the child's diabetes medication or meals. The most common and appropriate time for dental appointments in these patients is mid-morning as they usually take their medications following breakfast. Hence, a 2-h fasting period and a 1-h dental appointment during mid-morning ensure that the child's lunch time and medication dose are not disturbed. Consultation with the endocrinologist is advised if the fasting periods are expected to interfere with scheduled meals or medications. Nitrous oxide administration in diabetic children is the same as in healthy children with emphasis on pre- and post-oxygenation.

\section{Intellectual disability}

Uncooperative behavior and oro-motor sensitivity with gagging are common in children with intellectual disability leading to unique challenges faced by these children during dental appointments. Inhalational nitrous oxide is an indispensable tool for dentists treating these children. It can help to prevent dental care under general anesthesia and the associated risks. Nitrous oxide inhalation is a vital anxiolysis technique along with behavioral guidance in children with intellectual disability if they are able to tolerate the delivery hood over their face and nose.

Nitrous oxide is particularly effective in eliminating or minimizing extreme gagging. It is helpful to decrease the gag reflex during dental impressions, radiographs, or other procedures. In children with cognitive impairment, facial expressions, and gestures, reassuring physical contact, videos, models, and tell-show-do can play a crucial role in alleviating dental anxiety. Inhalational nitrous oxide is an advantageous adjunct to basic behavior guidance and verbal and nonverbal communicative strategies in providing effective dental care for children with intellectual disabilities. Nitrous oxide administration in children with intellectual disabilities is the same as for healthy children with pre- and post-oxygenation.

\section{Congenital and acquired heart disease}

In children with congenital or acquired heart diseases, preventive and restorative dental care is essential for maintenance of optimum oral health and function. The morbidity and mortality in these children are increased in the presence of oral diseases, since the oral cavity serves as a portal of entry for microbial infection that can 
cause bacteremia. In case of severe oral disease, the child's nutrition can be impaired resulting in a detrimental impact on the child's growth and function.

Untreated dental disease in these patients is a source of discomfort and/or pain as well as odontogenic infection. Dental treatments can be a cause of anticipated pain and dental anxiety. The compounding effect of untreated dental disease and the anxiety arising from anticipated dental treatment have the potential to compromise the hemodynamic stability. The use of inhalational nitrous oxide as an adjunct along with basic behavior guidance techniques should be considered to alleviate dental fear and anxiety and maintain clinically safe cardiovascular parameters in children with cardiac conditions.

Technical considerations For alleviating dental anxiety to provide optimum dental care, inhalational nitrous oxide can be used only after obtaining a detailed medical history and consultation with pediatric cardiologist. Delivery of $100 \%$ oxygen before the appointment followed by delivery of a minimum of $50 \%$ oxygen during the nitrous oxide administration and $100 \%$ oxygen for at least 5 min after completion of the appointment is crucial.

Monitoring of oxygen saturation using a pulse oximeter is necessary for children with cyanotic as well as acyanotic cardiac conditions to ensure that the oxygen saturation remains at or above $95 \%$, or at the baseline oxygen saturation specific for the patient. Specifically, the treatment of children with cyanotic cardiac conditions in a non-hospital setting should be discussed and cleared with the patients' cardiologist. When considering inhalational nitrous oxide in children with heart disease, all precautionary measures for prevention of bacterial endocarditis and coagulopathies should be implemented along with the nitrous oxide protocol.

\section{Down syndrome}

Children with Down syndrome are likely to benefit from the anxiolysis produced by inhalational nitrous oxide. Maxillary retrognathia, macroglossia, atlanto-axial instability, and nasal congestion are factors to keep in consideration when assessing patient selection.

\section{Cleft palate}

Oro-antral communication is prevalent in children with cleft palate which can dilute the inhaled concentration of nitrous oxide. An acrylic obturator worn by the child (Fig. 4) or a 2 -inch $\times 2$-inch piece of gauze tied with an 18-inch long dental floss placed superficially within the cleft can be used to prevent nitrous oxide dilution.

\section{Spinal deformities}

Children with spinal deformities can have abnormal chest and breathing movements due to the associated postural changes or mechanical anomalies. Identification of these changes is important before planning delivery of dental treatment. Limited 
Fig. 4 Obturator for cleft palate

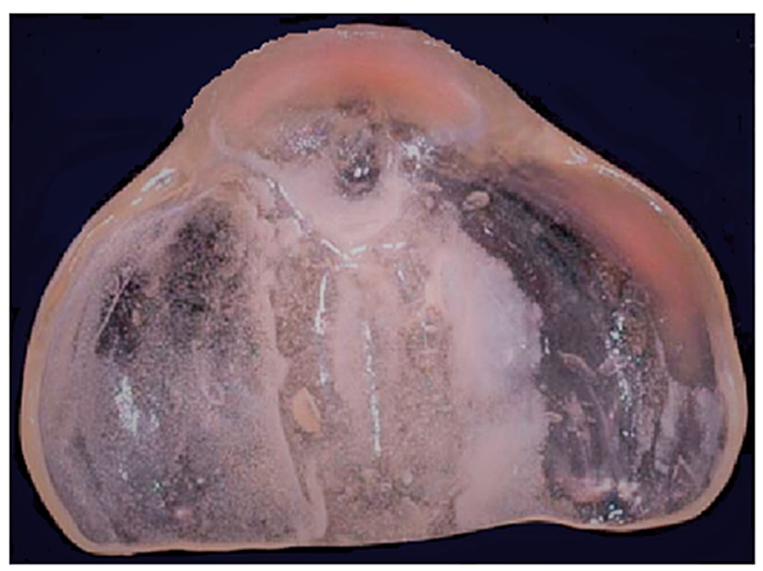

chest flexibility and abnormal ventilation is common in children with scoliosis or kyphosis.

\section{Chest deformities}

Children having chest malformations like spastic contractures, pectus excavatum, or neuromuscular disorders involving the respiratory muscles often experience ventilation issues. In such patients, consultation with the pediatric pulmonologist is recommended prior to the use of nitrous oxide for dental care.

\section{Pitfalls and complications}

- In light of the COVID-19 pandemic, use of single-use disposable nitrous oxide circuits, tubing, and hose is recommended. The reservoir bag should be sterilized as per the manufacturers' instructions.

- Should a patient exhibit nausea, the nitrous oxide should be dialed down to zero and $100 \%$ oxygen should be administered.

- High concentrations of nitrous oxide should be avoided to the minimize the risk for laryngospasm.

- The minimum concentration of inhalational nitrous oxide for the shortest duration should be utilized on a case-by-case basis.

\section{Further Reading}

1. K. Gupta et al. (eds.), Nitrous Oxide in Pediatric Dentistry, https://doi.org/https://doi. org/10.1007/978-3-030-29618-6_7 Use of Nitrous Oxide in Children with Special Health Care Needs 
2. Malamed S, editor. Chapter 37. Sedation—a guide to patient management. 6th edn. Elsevier; 2018. p. 529

3. American Psychiatric Association (2013) Diagnostic and statistical manual of mental disorders, 5th edn. American Psychiatric Association, Arlington, VA

4. Alrayyes S, Compton AA, Kawar N (2018) Oral health considerations for pediatric patients with sickle cell disease. Dis Mon 64(6):302-305

5. Little J, Miller C, Rhodus N. Chapter 22. Little and Falace's dental management of the medically compromised patient, 9th edn. Elsevier; 2017

6. Malamed SF, Orr DL (2014) Medical emergencies in the dental office, 7th edn. Elsevier, St. Louis, Missouri

7. Use of nitrous oxide for pediatric dental patients (2018) Pediatr Dent 40(6):281-286

Publisher's Note Springer Nature remains neutral with regard to jurisdictional claims in published maps and institutional affiliations. 